\title{
CORRIGENDUM
}

\section{Regulation of SV40 large T-antigen stability by reversible acetylation}

T Shimazu, Y Komatsu, KI Nakayama, H Fukazawa, S Horinouchi and M Yoshida

Oncogene (2014) 33, 3886; doi:10.1038/onc.2014.176

Correction to: Oncogene (2006) 25, 7391-7400; doi:10.1038/ sj.onc.1209731; published online 12 June 2006

Since the publication of this article, the authors found that Figures $1 \mathrm{c}$ and $3 \mathrm{c}$ had been incorrectly presented. The corrected

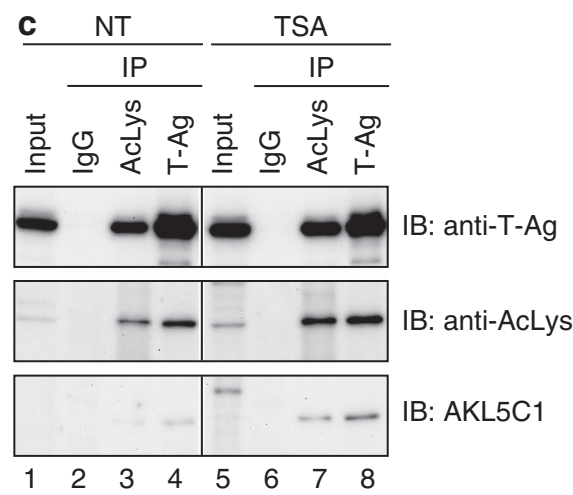

Figure 1. figures are shown below. These changes do not affect any of the results or conclusions of the study. The authors apologize for any confusion this error might have caused.

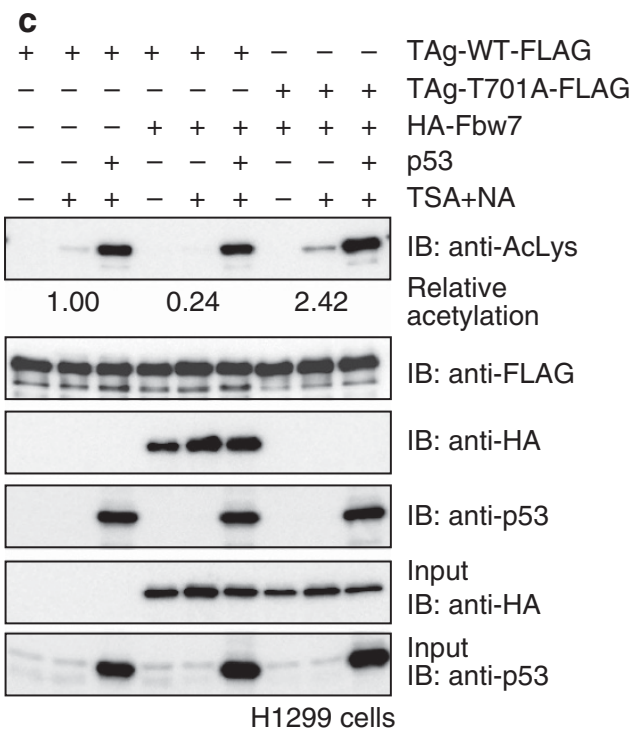

